\title{
A user-centred approach to developing bWell, a mobile app for arm and shoulder exercises after breast cancer treatment
}

\author{
Helena Harder ${ }^{1}$ (D) Patrick Holroyd ${ }^{2} \cdot$ Lynn Burkinshaw ${ }^{1} \cdot$ Phil Watten $^{2} \cdot$ \\ Charles Zammit $^{3}$ • Peter R. Harris ${ }^{4}$. Anna Good ${ }^{4}$ - Val Jenkins ${ }^{1}$
}

Received: 1 December 2016 / Accepted: 10 July 2017 / Published online: 24 July 2017

(C) The Author(s) 2017. This article is an open access publication

\begin{abstract}
Purpose The study aim was to develop a mobile application (app) supported by user preferences to optimise selfmanagement of arm and shoulder exercises for upper-limb dysfunction (ULD) after breast cancer treatment.

Methods Focus groups with breast cancer patients were held to identify user needs and requirements. Behaviour change techniques were explored by researchers and discussed during the focus groups. Concepts for content were identified by thematic analysis. A rapid review was conducted to inform the exercise programme. Preliminary testing was carried out to obtain user feedback from breast cancer patients who used the app for 8 weeks post surgery.

Results Breast cancer patients' experiences with ULD and exercise advice and routines varied widely. They identified and prioritised several app features: tailored information, video demonstrations of the exercises, push notifications, and tracking and progress features. An evidence-based programme was developed with a physiotherapist with progressive exercises for passive and active mobilisation, stretching
\end{abstract}

Electronic supplementary material The online version of this article (doi:10.1007/s11764-017-0630-3) contains supplementary material, which is available to authorized users.

Helena Harder

h.harder@sussex.ac.uk

1 Sussex Health Outcomes Research and Education in Cancer (SHORE-C), Brighton and Sussex Medical School, University of Sussex, Brighton, UK

2 School of Engineering and Informatics, University of Sussex, Brighton, UK

3 Brighton and Sussex University Hospitals NHS Trust, Brighton, UK

4 School of Psychology, University of Sussex, Brighton, UK and strengthening. The exercise demonstration videos were filmed with a breast cancer patient. Early user testing demonstrated ease of use, and clear and motivating app content.

Conclusions bWell, a novel app for arm and shoulder exercises, was developed by breast cancer patients, health care professionals and academics. Further research is warranted to confirm its clinical effectiveness.

Implications for cancer survivors Mobile health has great potential to provide patients with information specific to their needs. bWell is a promising way to support breast cancer patients with exercise routines after treatment and may improve future self-management of clinical care.

Keywords Breast cancer - Shoulder function . Lymphoedema $\cdot$ Exercise $\cdot$ mHealth $\cdot$ Mobile app . Rehabilitation

\section{Introduction}

Axillary treatment for breast cancer, which is surgical removal of the lymph nodes in the armpit (axilla) or axillary radiotherapy, can contribute to upper limb dysfunction (ULD). Symptoms of ULD include pain, numbness, decreased shoulder range of motion (ROM), reduced strength, joint restrictions, axillary web syndrome (lymphatic cording), and development of arm volume changes or lymphoedema due to interruption or damage to the axillary lymphatic system [1-7]. Severity of symptoms and prevalence vary considerably because of differences in diagnostic criteria, assessment methods and time points among studies. However, research data show that half of patients report at least one moderate-to-severe symptom in the first 18 months post surgery $[8,9]$. For the majority, symptoms decrease over time, but for some, they are more persistent or develop later [10-14]. More extensive 
treatment is usually associated with greater morbidity. Common predictors for limitations include mastectomy, axillary lymph node dissection or clearance, higher body mass index and adjuvant therapy (i.e. axillary radiotherapy) $[9$, 15-20]. ULD is often found to be related to functional limitations in work or social/recreational activities, and psychosocial burdens such as negative affect and reduced quality of life (QoL) [14, 20-27].

Multifactorial physical therapy (e.g. specific passive and active mobilisation or stretching exercises) after breast cancer treatment has proven to be safe and effective [28-31]. Exercises can alleviate symptoms, restore shoulder function and contribute to better QoL, especially if it is implemented early postoperatively $[28,32-35]$. In the UK, the National Institute for Health and Clinical Excellence clinical guidelines recommend to provide breast cancer patients with information about the risks of developing lymphoedema and the benefits of exercise [36]. Most patients lack access to an exercise or rehabilitation programme led by a physiotherapist or other health care professional (HCP) [37]. Routine care in many breast cancer centres is information provision and patient education, usually in the form of generic information sheets with exercise instructions or breast cancer charity leaflets or DVDs (e.g. 'Exercises after breast cancer surgery' from Breast Cancer Care [38]). However, there appears to be a wide variation in the exercise recommendations for shoulder mobilisation [39, 40], and adherence can be low because it is challenging for many patients to perform the exercises at home without (in-person) training or support [41, 42]. This indicates that there is a need to improve the self-management of postoperative arm and shoulder exercises for breast cancer patients. Self-management refers to the engagement of patients in managing the medical, behavioural and emotional consequences of their long-term disease [43]. It emphasises patients' control over their disease and is beneficial in terms of patient activation and self-efficacy [44].

In recent years, the widespread adoption and use of mobile technologies is opening new and innovative ways to improve health and health care delivery $[45,46]$. A promising way of supporting the delivery of cancer care is the use of mobile health (mHealth) [47]. mHealth can be described as medical or public health practice supported by mobile or other wireless devices [48]. Smartphones and mobile application (apps) have become an integral part of everyday life for an increasing number of people. Seventy-seven percent of all adults in the UK own a smartphone with the average user spending $25 \mathrm{~h}$ online each week [49]. There are now around 165,000 healthrelated apps available for the two major mobile device software platforms: Apple's iOS (i.e. iPhone Operating System) and Google's Android [50]. This includes hundreds of cancerrelated apps which were designed for several purposes such as increasing awareness, providing information or managing side-effects [51-53].
Although mHealth tools have been suggested as having the potential to impact on supportive care and self-management, most apps are under-used [54, 55]. Only few developers have engaged target users and HCPs in its development to ensure that the content of the app is evidence-based and theoretically informed, and that desired information and features are included to enable early adoption and implementation $[51,52,56]$. The purpose of the present study was to design and develop a mobile app together with target users to support selfmanagement of arm and shoulder exercises following breast cancer treatment. This paper documents the development process of this app (bWell) and preliminary results of early user testing.

\section{Methods}

The study was conducted in two sequential phases. The study objective of phase 1 was to design bWell using a user-centred approach and to build and test the prototype [57]. In phase 2, feedback was collected from a small group of breast cancer patients who used the app post surgery. Study approvals were gained from the National Research Ethics Service (NRES) Committee London-Camberwell St Giles and Brighton (phase 1; REC ref.: 14/LO/1797), NRES Committee North West-Greater Manchester West and Sussex University Hospitals NHS Trust (phase 2: REC ref.: 15/NW/0814) and Sussex University Hospitals NHS Trust. A multidisciplinary team was involved in the study project (including a physiotherapist, a breast surgeon, (health) psychologists and digital media technologists), and regular project meetings were held.

\section{Focus groups with breast cancer patients}

\section{Design and setting}

A qualitative research design and focus group methodology were chosen to collect user needs and preferences for the content and features of bWell $[58,59]$. Focus groups allow for experiences and multiple views to be shared and discussed, and allow for consensus on a topic to be explored [60]. Two serial focus groups with breast cancer patients were conducted at Sussex Health Outcomes Research and Education in Cancer (SHORE-C) at the University of Sussex in Brighton. The focus groups were facilitated by members of the research team who had experience in conducting focus groups or user-led development of mobile apps.

\section{Sample and recruitment}

Women with early-stage breast cancer (I-IIIA) who completed surgery, were aged 18 years or older and were able to provide written informed consent were eligible for study 
participation. Participants were recruited between January and March 2015 during follow-up visits in the local breast cancer clinic (Park Centre for Breast Care in Brighton) and through provision of recruitment flyers in the clinic's waiting room and breast cancer support groups. Those who were interested were given a study information pack and were asked to return the expression of interest (EOI) form with contact details by email or freepost. Potential participants were provided with further study details and screened over the phone to determine study eligibility. Out-of-pocket expenses (i.e. travel by taxi or own transport to attend the focus groups) were reimbursed. All participants were provided with a $£ 25$ voucher as thank you gift for the research participation.

\section{Data collection}

Written informed consent was obtained from participants before commencement of the first focus group. Participants completed a demographic sheet providing background details, including breast cancer diagnosis and treatment, and information on their use of mobile devices. At the start of each focus group, the facilitators $(\mathrm{HH}, \mathrm{PH})$ introduced the project, outlined the objectives and highlighted the general ground rules.

Semi-structured topic guides were used to frame the group discussions. Topics of the first focus group (March 2015) included previous experiences of breast cancer treatment (i.e. axillary treatment, ULD), experiences with the arm and shoulder exercises (e.g. information provision, previous experiences) and desired app content and features (e.g. views on background information, images/text exercises). Inclusion and preference for adoption of exercise behaviour change techniques (BCT), such as goal setting, feedback on behaviour, methods for data capture and reminders, were also discussed. A list of potential BCTs for the app were selected by the researchers (PRH, $\mathrm{AG}, \mathrm{HH})$ after searching literature and studies that used BCTs to promote self-care or selfmanagement of exercise.

The results of the first discussion were used to develop a wireframe of bWell and mock-up screenshots. Wireframes are basic visual schematics that represent the framework or layout of an app, and are used to develop screen functionality, content layout and priority or sequencing of what needs to happen with the app. Sample screenshots are used in design studies to gather valuable user feedback on overall usability issues (e.g. layout, font size, colour) prior to the final design stage [61, 62]. During the second focus group (June 2015), a series of (PowerPoint) slides illustrating different pages of the app was presented to the whole group and used to encourage opinions and further discussion. Topics included acceptability and attractiveness of features, potential concerns and recommendations for improvements. The facilitator guided participants through each screen, probing for understanding, expectations and areas of confusion. Observations were documented, and in addition, field notes were made by an independent observer. At the end of each session, facilitators reflected their interpretations to the participants to support the credibility of the data interpretation. Each focus group lasted about $1 \mathrm{~h}$.

\section{Data analysis}

The focus groups were audio recorded and transcribed verbatim with participants' permission. Descriptive statistics were used to analyse demographic and other quantitative data. All qualitative data was coded and arranged in themes using thematic analysis [63]. The analysis was framed by the core focus group topics. Transcripts were read through several times to identify categories or themes $(\mathrm{HH}, \mathrm{PH})$. After initial coding highlighting relevant discussion themes, all text segments were iteratively analysed. Themes were added or merged until they effectively represented all text segments and captured the essence of the discussion [64]. The coding frame was refined with discussions about areas of disagreement and consensus, and any differences in interpretation were reconciled. Comments on user needs and preferences and app usability were classified using the following classifications: content and information (e.g. relevant outcome variables, exercises, functionalities or written information), navigation and structure (e.g. location where information is located) and design and presentation (e.g. use of colour, graphs, amount of text). The study team reached consensus on the content and features that would be included in the app. Considerations for requirement selection (i.e. which features to include) included the number of participants who mentioned it, the context of use, overlap/ integration with existing information, technical feasibility and finance and time available to realise the requirement.

\section{Development of the arm and shoulder exercise programme}

An evidence-based exercise programme was developed together with a chartered physiotherapist. A rapid review was conducted to search for (clinical practice) guidelines of arm and shoulder exercises for breast cancer patients [65]. Search terms (e.g. physiotherapy, exercise, rehabilitation, shoulder, upper limb, mastectomy, breast cancer surgery, range of motion/ROM) and resources (e.g. Scopus, EMBASE, MEDLINE, CINAHL, Cochrane database of systematic reviews, Chartered Society of Physiotherapist) were selected, and the results were viewed and summarised by the research team (LB, HH). In addition, information for breast cancer patients (i.e. hospital exercise information sheets, charity leaflets or DVDs) was examined. Both rapid reviews informed the content and structure of the programme. Features of exercise programmes, such as information on initiation (e.g. early or delayed) and progression (e.g. passive vs. active movements, 
number of stages in the programme), frequency (e.g. number of repetitions and session per day) and range of motion (below or above shoulder level), were extracted and discussed in detail.

\section{Preliminary early user testing}

The feasibility of using bWell after surgery for breast cancer was evaluated in a small group of patients to improve content quality and to evaluate the content interface (visual design) and ease of use. Recruitment took place in the breast cancer clinic via recruitment flyers and/or invitation from a breast cancer surgeon or oncologist. Potential participants registered their interest in the study either via email or an EOI form. They subsequently received a telephone call from the research team to discuss content, study procedures and consent. Selection criteria included the following: newly diagnosed with earlystage breast cancer; treated with surgery (i.e. lumpectomy or mastectomy without immediate reconstruction); being a smartphone user (iPhone model 4-6s); age 18 years or older; ability to provide written informed consent. Participants received a code to download bWell on their mobile device via Apple's digital distribution platform (detailed instructions were provided via email and a video demonstration on YouTube). Participants were asked to use the app for 8 weeks and were sent a study-specific questionnaire at the end of the study. This questionnaire was developed to capture user feedback and evaluate content and functionality (including ratings) and explored areas of improvement to incorporate in the final design of bWell (Supplementary Fig. III). All participants provided written informed consent prior to start of the study.

\section{Results}

\section{Focus groups with breast cancer patients}

\section{Sample}

Nine women with early-stage breast cancer participated in the focus groups. Sample characteristics are displayed in Table 1. Participants were between 3 and 18 months post diagnosis, and age ranged from 47 to 65 years. All women had a smartphone or tablet computer, and five used apps on a regular basis. Themes of the focus groups are presented in Table 2 and Supplementary Table I, including typical comments in each category for illustration.

\section{Experiences with arm and shoulder exercises}

Experiences with axillary treatment and arm and shoulder exercises varied widely (see Table 2). Most patients (7/9) were
Table 1 Sample characteristics focus groups

\begin{tabular}{|c|c|}
\hline \multicolumn{2}{|l|}{ Socio-demographics characteristics } \\
\hline Age, mean (SD) & $52.3(5.7)$ \\
\hline \multicolumn{2}{|l|}{ Education $(n)$} \\
\hline Primary/secondary school & 2 \\
\hline College degree & 1 \\
\hline University degree & 6 \\
\hline \multicolumn{2}{|l|}{ Living arrangements $(n)$} \\
\hline Alone & 6 \\
\hline With partner & 3 \\
\hline \multicolumn{2}{|l|}{ Occupational status $(n)$} \\
\hline Working & 7 \\
\hline Not working & 2 \\
\hline \multicolumn{2}{|l|}{ Health characteristics } \\
\hline Months since diagnosis, mean (SD) & $12.1(6.3)$ \\
\hline \multicolumn{2}{|l|}{ Type of treatment $(n)$} \\
\hline Surgery only & 2 \\
\hline Surgery, adjuvant treatment ${ }^{a}$ & 7 \\
\hline \multicolumn{2}{|l|}{ Mobile device user experience } \\
\hline \multicolumn{2}{|l|}{ Mobile device use $\mathrm{e}^{\mathrm{b}}$ (daily average), $n$} \\
\hline $30-60 \mathrm{~min}$ & 5 \\
\hline $1-2 \mathrm{~h}$ & 2 \\
\hline$>2 \mathrm{~h}$ & 2 \\
\hline \multicolumn{2}{|l|}{ Use of mobile device features $(n)$} \\
\hline Text messaging & 9 \\
\hline Apps & 5 \\
\hline Internet browsing & 6 \\
\hline Camera & 8 \\
\hline Games & 2 \\
\hline Other $^{\mathrm{c}}$ & 4 \\
\hline
\end{tabular}

${ }^{\mathrm{a}}$ Six of nine received adjuvant treatment at time of study (radiotherapy 2, Herceptin 1, tamoxifen 3)

${ }^{\mathrm{b}}$ All patients used a mobile phone, and seven of nine used a tablet computer

${ }^{\mathrm{c}}$ Other: alarm, email, social media

informed about the exercises by a HCP (surgeon or breast care nurse), but some indicated that the information and instructions they received was partial and felt they needed more direction. Others commented on the inconsistency among HCPs regarding management of ULD and showed dissatisfaction with the advice they received about the exercises, and care and use of their affected arm. Some were confused or frustrated by this conflicting information. Most agreed that the lack of consistent advice was related to the treatment trajectory such as being monitored by different HCPs (surgeon, oncologist) in a relatively short time.

A key finding was that all women were aware of the importance of the exercises for their recovery and performed them daily in the first weeks post surgery. Some were surprised about the intensity of ULD symptoms and how it affected their everyday life. Most realised that the exercises are 
Table 2 Results focus group: experiences with ULD and the arm and shoulder exercises

\begin{tabular}{|c|c|}
\hline Emerging themes & Representative quotes \\
\hline $\begin{array}{l}\text { Awareness of importance of } \\
\text { exercises }\end{array}$ & $\begin{array}{l}\text { - I can't remember if I was told at discharge [about exercises] ... but it was in } \\
\text { the pack and I just read everything in there because my movement is really } \\
\text { crucial to my job and my livelihood, so I was scared stiff of not being able to } \\
\text { move properly. I started them straight away and yes they are painful, but one } \\
\text { year on they have made a difference. [Participant 6] } \\
\text { - I went a few steps ahead. I had breast conserving surgery and moved on, } \\
\text { thought 'I'm fine' until I was driving and had to get into tight spaces. I didn't } \\
\text { realise how much it was affecting me. It's hard to measure it. [Participant 5] }\end{array}$ \\
\hline $\begin{array}{l}\text { Awareness that exercises are } \\
\text { ongoing }\end{array}$ & $\begin{array}{l}\text { - It's an ongoing exercise, to do them all the time, to keep them going } \\
\text { [Participant 2] } \\
\text { - Initially I was really good [doing the exercises] they were all impressed. I was } \\
\text { moving on and it was only } 4 \text { or } 5 \text { months later, I was doing something and } \\
\text { thought 'oh the pain' ... and only since then have I started to do the exercises } \\
\text { again and it is a lot better. [Participant 1] }\end{array}$ \\
\hline $\begin{array}{l}\text { Lacking or inconsistent } \\
\text { advice }\end{array}$ & $\begin{array}{l}\text {-I wasn't told about it ... I knew about it because a friend had been diagnosed } \\
\text { before and she lent me a DVD she had been given } 3 \text { years ago. The BCN } \\
\text { didn't specifically mention it, and I'm quite surprised because she was } \\
\text { thorough in any other way [Participant 7] } \\
\text {-I had the BCN and surgeon saying 'Start the day after [surgery]', but then the } \\
\text { district nurse visited and said 'You only just had surgery, don't worry about } \\
\text { it.' Then I saw my oncologist ... He was concerned about cording and } \\
\text { advised to go swimming. Two days later I saw the surgeon and BCN, and } \\
\text { they said 'Absolutely no way that you should go swimming!' ... I was terribly } \\
\text { upset and felt that I failed. [Participant 4] }\end{array}$ \\
\hline $\begin{array}{l}\text { Gaps in care pathway and } \\
\text { follow-up }\end{array}$ & $\begin{array}{l}\text { - Nobody asked anything about it at all. It was very much here you go do your } \\
\text { things [Participant 8] } \\
\text { - I'm about to start chemotherapy and my nurse said 'Well that's it, I won't be } \\
\text { seeing you for a while'... There are different BCNs, no regular } \\
\text { appointments. The focus is on chemo now and not my arm [Participant 4] }\end{array}$ \\
\hline $\begin{array}{l}\text { Need for more directions or } \\
\text { physiotherapy }\end{array}$ & $\begin{array}{l}\text { - I remember just getting through it and not speaking to anyone [about } \\
\text { exercises] I had to get through it and just do it [Participant 2] } \\
\text { - I was really surprised that there was no intervention from the physio. I } \\
\text { thought that the two would be really well connected, but there's no } \\
\text { connection with physio at all! [Participant 3] }\end{array}$ \\
\hline
\end{tabular}

$B C N$ breast care nurse, $U L D$ upper limb dysfunction ongoing and have to be continued long after treatment, sometimes because of fear of developing (recurrent) ULD symptoms. Suggestions for information on how to manage expectations towards exercises, and reassurance about what can be expected after treatment, were recommended by participants.

\section{User needs and requirements for bWell}

A detailed overview of the functionalities to improve rehabilitation after axillary treatment is displayed in detail in Supplementary Table I. All participants expected that bWell would be of clinical benefit for breast cancer patients, and most commented that a mobile app would have supported them after treatment. Some proposed app features were more prominent; in particular, the use of reminders or push notifications to trigger exercise sessions emerged several times in the discussion and was viewed as very useful for the app. Participants also referred to a need for tailored information on ULD and the arm and shoulder exercises, and thought that this would promote recovery. There was a strong preference for video demonstrations (i.e. instruction videos of each individual exercises, and a longer video for each stage with the exercises performed in a sequence) including verbal instructions to help patients understand and safely perform the exercises at home. Some suggested adding a timer function to the exercises and a possibility to repeat them. Most women highlighted that it was important the videos would provide reassurance about abilities, and motivate patients.

Participants valued functions for feedback and selfmonitoring and mentioned that for example a tracking feature to self-rate well-being (emotional, physical) and a visual display (e.g. a personal graph) would be encouraging, increase awareness and be helpful to see change over time. They stated that the timing and frequency of the reminders needed to be well designed so that they could be customised by the users. The majority of participants expressed concerns about using 
goal setting features. Some remarked that if predetermined outcome goals were not achieved, this could have a negative impact on motivation and emotional status. A function for system reward (e.g. stars) for user engagement was mentioned by one participant. Some women also considered that features for sharing personal information (i.e. feature that enables users to communicate with each other, receive/ask for tips, advice or encouragement from other patients, such as a chat feature, comment area or 'like' option) could be beneficial and motivating in certain circumstances.

\section{Feedback on wireframe and screenshots}

The second focus group with six of nine participants centred on feedback on wireframes and mock-up sample screenshots for bWell to validate usability and explore design ideas. Initial feedback on wireframes and screenshots was very positive and helped to clarify some design concepts. Participants commented on the self-monitoring feature (i.e. scales for pain, flexibility and mood) and suggested to rephrase the mood scale and colour-code the ratings. All agreed that one rating a day would be sufficient to keep a record of progress. They also recommended the inclusion of a diary function for selfevaluation of symptoms (e.g. a notes feature in which users can create/edit and store notes) so they could register events for certain days on the calendar. It was suggested that a brief section with tailored information (e.g. a list of common problems) and a FAQs section would benefit users. Participants commented on an exercise demonstration video and recommended that the model should have an 'everyday-look' (e.g. plain clothes, jewellery). Also a choice of models of different ages to engage a wider range of patients and help them to relate or identify with the model was proposed. Suggestions from the second focus group were discussed by the research team and used to generate the final user needs and system requirements for bWell.

\section{Development of the arm and shoulder exercise programme}

\section{Framework for the exercise programme}

A rapid review of relevant literature and guidelines identified several programmes for arm and shoulder mobilisation after breast cancer treatment but also showed a wide variability regarding content and structure of the exercises $[28,30,31$, $66]$. There was no consensus on intervention duration, frequency of training, training volume (number of sets and repetitions) and progression of exercises to more advanced performance levels. Information on strategies to facilitate adherence was lacking. Most studies recommended early initiation of exercises (i.e. within 1-3 days post surgery) to avoid deterioration of full shoulder ROM, and a delayed approach to full mobilisation (i.e. limited movement of the arm below $90^{\circ}$ up till 7-10 days post surgery) [28, 34, 66-70]. Data also showed growing support for the use of progressive resistance training and weight training at a later stage as both were considered safe and efficacious in breast cancer rehabilitation [29, 33, 71-73]. Based on a rapid evidence assessment, an exercise programme for bWell was developed which incorporated three key stages of exercise progression with the aim to maintain/increase ROM, facilitate lymphatic transport and increase strength and stability of the affected arm and shoulder:

- Stage 1: early post-operative exercises for passive mobilisation (six active assisted exercises below shoulder level) starting the first day after surgery

- Stage 2: intermediate post-operative exercises for active mobilisation and stretching (four exercises above shoulder level) starting after 1 week after surgery or when the drains are removed

- Stage 3: late post-operative exercises for muscle strengthening and sustained stretching (five exercises) starting 46 weeks after surgery depending on wound healing and recovery

The exercises were chosen for their ability to be performed independently without special equipment. They included mobilisation in all planes of motion, including flexion, extension, adduction, abduction and internal/external rotation. Stage 3 included exercises with weights (or similar household objects such as cans or small water bottles) and a series of Pilates exercises which were demonstrated to be effective and safe in studies with breast cancer patients [74-76]. All sessions were initiated with warm-up exercises, and cooldown exercises were recommended at the end of each session. Three sets of five repetitions (stages 1 and 2) or two sets of 10 repetitions (stage 3 ) were recommended prior to moving on to the following exercise. Each exercise stage would take approximately $15 \mathrm{~min}$ to complete. In line with other programmes, the bWell exercises were not suitable for patients who had immediate breast reconstruction.

\section{Filming the exercise demonstration videos}

Videos of the arm and shoulder exercises were produced by the Media Technology Lab at the University of Sussex and filmed with a multicamera setup against a solid white background (Supplementary Fig. I). These videos were used as visual demonstration of how to perform each exercise (17 in total including a warm-up and cool-down exercise) and to help patients understand the exercises for each postoperative stage. Exercises for each stage were also filmed in a sequence to provide a class to follow along. The exercises were demonstrated by a female volunteer who had breast cancer surgery 9 months before filming. All videos were scripted 
by the researchers and reviewed by a breast cancer patient and adjusted accordingly. Language for film scripts and content text was adapted to be clear and concise by use of short sentences, subheadings and highlighted text. Film script included reminders about exercising within the pain-free range and without discomfort, and to maintain good body alignment for core stabilisation. Text to reassure patients about exercise level and ability was also added. The content of the videos was checked by the physiotherapist to assure that the exercises were performed correctly. All videos were edited and included in bWell, together with text-based material for each exercise and stage (see Table 3 and screenshots in Supplementary Fig. II).

\section{Building bWell}

After evaluation of the wireframes and mock-up screenshots, alterations to the functional specifications and user interface design of bWell were made in accordance with the recommendations. Technical requirements were derived, after which the first prototype was developed (see Table 3 and Supplementary Fig. II). bWell was built using Swift programming language with the Xcode IDE [78, 79]. Quality control testing was carried out by the developers (PH, PW) throughout the development process to ensure that all content and features were functioning properly. bWell version 1.0 was submitted to a digital distribution platform (App Store) via an iOS Developer Account.

\section{Preliminary early user testing}

Between January and March 2016, four breast cancer patients contacted the research team and provided consent for early testing. One woman had technical problems with downloading the app on her iPad and withdrew from the study. Participants were aged between 51 and 58 years, had completed surgery (i.e. lumpectomy and sentinel node biopsy) and were scheduled for radiation treatment. All used bWell on an iPhone 5, almost daily or several times per day, in preparation for their radiotherapy. They found navigation easy and reported no technical issues. Content text and font size were clear and concise. Popular characteristics were the demonstration videos and reminder feature. Participants stated that the videos (including instructions) were very useful and clear. Self-monitoring and feedback on outcomes (self-rating and visual graphs) were viewed or seen as somewhat useful. Open-ended feedback indicated that especially the graded tasks and different stages of the exercise programme were beneficial for recovery from treatment. All women reported that the app kept them motivated and engaged, and would definitely recommend bWell to other breast cancer patients (average star rating: 4.6/5).

\section{Discussion}

This paper presents a user-centred approach and cocreation process of bWell, a mHealth app for breast cancer patients. The importance of engaging users in the design and conduct of mHealth interventions is well recognised as it facilitates app adoption and usage [80, 81]. This project is one of few to involve patients in the development process and a first step in optimising selfmanagement of ULD in patients with breast cancer.

Table 3 bWell content and behaviour change techniques

\begin{tabular}{|c|c|c|}
\hline Feature content & Description & Behaviour change technique $^{\mathrm{a}}$ \\
\hline Information provision & $\begin{array}{l}\text { Information about ULD, the recovery stages and all } \\
\text { individual exercises based on evidence-based guidelines }\end{array}$ & Education/information \\
\hline Video demonstrations & Detailed video instructions of each exercise and each recovery stage & Demonstration of behaviour \\
\hline Graded tasks & $\begin{array}{l}\text { Progressively more difficult exercises to increase arm/shoulder ROM } \\
\text { and strength }\end{array}$ & Education/information \\
\hline Record exercises performed & Calendar feature to record if each session of exercises was performed & Monitor and record behaviour \\
\hline Motivational statements & Verbal instructions (including messages for reassurance) for each exercise & Motivation \\
\hline $\begin{array}{l}\text { Push notifications, including } \\
\text { opt-in opt-out option }\end{array}$ & $\begin{array}{l}\text { Self-setting reminder function to prompt patient daily to access next exercise } \\
\text { session to increase engagement and user retention }\end{array}$ & Motivation \\
\hline $\begin{array}{l}\text { Behaviour and progress } \\
\text { tracking }\end{array}$ & $\begin{array}{l}\text { Self-rate pain, flexibility and mood each day that the app is used with visual } \\
\text { display in calendar to see change over time }\end{array}$ & $\begin{array}{l}\text { Self-monitoring of outcome/feedback } \\
\text { on outcome of behaviour }\end{array}$ \\
\hline Diary function & Diary function in calendar to allow reflection on daily function & Self-monitoring of behaviour \\
\hline Section FAQs & $\begin{array}{l}\text { Questions about the purpose of bWell, e.g. technical issues, emails, } \\
\text { non-technical user questions }\end{array}$ & Education/information \\
\hline Web links & $\begin{array}{l}\text { Web links to contact information about breast cancer related resources } \\
\text { or support }\end{array}$ & Education/information \\
\hline
\end{tabular}

$U L D$ upper limb dysfunction

${ }^{\mathrm{a}} \mathrm{BCTs}$ as described and classified by Michie et al. [77] 
ULD affects a great number of survivors, and specific exercises are recommended to restore full shoulder mobility and minimise symptoms or development of lymphoedema. bWell is a theory-informed mobile app that supports self-management of these exercise routines. The use of self-management programmes has been promoted to reduce symptoms, achieve better health-related outcomes and reduce the demand on health services and health costs $[82,83]$.

During the first phase of our study, we evaluated women's own experiences with breast cancer treatment and ULD. Results from the focus group showed that patients were aware of the importance of arm and shoulder exercises, but advice from HCPs was often inconsistent or sometimes lacking. Similar findings were observed by Lee et al. who examined perceptions of arm care and exercise advice in 175 breast cancer patients, 6 to 15 months after their surgery [84]. Women revealed concerns about ULD or fear of lymphoedema, and reported that standardised advice did not meet expectations.

Our study also identified barriers and motivators for adoption and continued use of an arm and shoulder exercise app in breast cancer patients. The top desired features among focus group participants were reminders and detailed video demonstrations of the exercises. Tailored information about ULD and tracking exercise and progress were also perceived to be helpful behavioural change features for bWell. Goal setting features were seen as a barrier in the uptake of the app. Results of early user testing showed that it is feasible to use the app after breast cancer surgery. Women commented on the easy navigation and clear content, and reported that they would definitely recommend the app to other patients.

The current study has some limitations. Study participants were self-selected and may have been more likely to be interested in the use of mobile technology. However, the focus groups included non-users of mobile apps which expanded the diversity of the group. We were also unable to include all user needs and requirements identified in the focus groups (e.g. social support function, motion capture device) in the current version of the app because of financial limitations. Lastly, early testing was conducted in a small sample of users. This was due to the limited time for this pilot project (12 months in total) which restricted recruitment, and because bWell is currently only available (as a free app without in-app purchases) for iOS devices which was a reason for non-participation for some women. Future work should include further development of bWell, such as including other mobile platforms (e.g. Android) and adding an online forum for social support, and collecting feedback about bWell from a large group of HCPs. Further research should also engage patients without mobile devices for example by providing them with a smartphone or tablet for the duration of the study.

\section{Conclusions}

bWell, a novel mobile app, was developed together with breast cancer patients to support self-management of arm and shoulder exercises following axillary treatment. Further evaluation in a randomised controlled trial is needed to provide objective evidence on its clinical effectiveness. This will allow us to optimise the usability of the app and to examine if it is feasible to use bWell as an integrated part of clinical care for breast cancer.

Acknowledgements We thank the patients for their invaluable contribution to the development of bWell, Alison White for demonstrating the exercises and Lucy Matthew and Shirley May for assisting in this research project.

\section{Compliance with ethical standards}

Funding This study was funded by a 12-month pilot grant from Breast Cancer Now (grant number 2014MaySP312) and additional funding from a local Charity Com Skills 4 Health.

Conflict of interest The authors declare that they have no conflict of interest.

Ethical approval All procedures performed in studies involving human participants were in accordance with the ethical standards of the institutional and/or national research committee and with the 1964 Helsinki Declaration and its later amendments or comparable ethical standards.

Informed consent Informed consent was obtained from all participants included in the study.

Open Access This article is distributed under the terms of the Creative Commons Attribution 4.0 International License (http:// creativecommons.org/licenses/by/4.0/), which permits unrestricted use, distribution, and reproduction in any medium, provided you give appropriate credit to the original author(s) and the source, provide a link to the Creative Commons license, and indicate if changes were made.

\section{References}

1. Caro-Moran E, Díaz-Rodríguez L, Cantarero-Villanueva I, Galiano-Castillo N, Arroyo-Morales M, Fernández-Lao C. Nerve pressure pain hypersensitivity and upper limb mechanosensitivity in breast cancer survivors: a case-control study. Pain Med. 2014;15: 1715-23.

2. Fukushima K, Aroucha Carmo L, Carvalho Borinelli A, Wanderley Souto Ferreira C. Frequency and associated factors of axillary web syndrome in women who had undergone breast cancer surgery: a transversal and retrospective study. SpringerPlus. 2015; doi:10. 1186/s40064-015-0889-7.

3. Harrington S, Padua D, Battaglini B, Mitchener LA. Upper extremity strength and range of motion and their relationship to function in breast cancer survivors. Physiother Theory Pract. 2013;29:513-20.

4. Johansen S, Fosså K, Besvold IL, Malinen E, Fosså SD. Arm and shoulder morbidity following surgery and radiotherapy for breast cancer. Acta Oncol. 2014;53:521-9. 
5. Merchant CR, Chapman T, Kilbreath SL, Refshauge KM, Krupa K. Decreased muscle strength following management of breast cancer. Disabil Rehabil. 2008;30:1098-105.

6. Monleon S, Ferrer M, Tejero M, Pont A, Piqueras M, Belmonte R. Shoulder strength changes one year after axillary lymph node dissection or sentinel lymph node biopsy in patients with breast cancer. Arch Phys Med Rehabil. 2016;97:953-63.

7. Verbelen H, Gebruers N, Eechhout F-M, Verlinden K, Tjalma W. Shoulder and arm morbidity in sentinel node-negative breast cancer patients: a systematic review. Breast Cancer Res Treat. 2014;144: 21-31.

8. Hayes SC, Rye D, Battistutta D, Newman B. Prevalence of upperbody symptoms following breast cancer and its relationship with upper-body function and lymphedema. Lymphology. 2010a;43: 178-87.

9. De Groef A, Van Kampen M, Tieto E, Schonweger P, Christiaens M-R, Neven P, et al. Arm lymphoedema and upper limb impairments in sentinel node-negative breast cancer patients: a one year follow-up study. Breast. 2016;29:102-8.

10. Bulley C, Coutts F, Blyth C, Jack W, Chetty U, Barber M, et al. Prevalence and impacts of upper limb morbidity after treatment for breast cancer: a cross-sectional study of lymphedema and function. Cancer Oncol Res. 2013;1:30-9.

11. Devoogdt N, Van Kampen M, Christiaens MR, Troosters T, Piot W, Beets N, et al. Short- and long-term recovery of upper limb function after axillary lymph node dissection. Eur J Cancer Care. 2011;20: $77-86$.

12. Kootstra JJ, Dijkstra PU, Rietman H, de Vries J, Baas P, Geertzen $\mathrm{JH}$, et al. A longitudinal study of shoulder and arm morbidity in breast cancer survivors 7 years after sentinel lymph node biopsy or axillary lymph node dissection. Breast Cancer Res Treat. 2013;139: 125-34.

13. Sagen A, Kaaresen R, Sandvik L, Thune I, Risberg MA. Upper limb physical function and adverse effects after breast cancer surgery: a prospective 2.5 -year follow-up study and preoperative measures. Arch Phys Med Rehabil. 2014;95:875-81.

14. Yang EJ, Kang E, Kim S-W, Lim J-Y. Discrepant trajectories of impairment, activity, and participation related to upper-limb function in patients with breast cancer. Arch Phys Med Rehabil. 2015;96:2161-8.

15. Hayes SC, Johansson K, Stout NL, Prosnitz R, Armer JM, Gabram $\mathrm{S}$, et al. Upper-body morbidity after breast cancer: incidence and evidence for evaluation, prevention, and management within a prospective surveillance model of care. Cancer. 2012;118:2237-49.

16. Hidding JT, Beurskens C, van der Wees P, van Laarhoven HW, Nijhuis-van der Sanden MW. Treatment related impairments in arm and shoulder in patients with breast cancer: a systematic review. PLoS ONE. 2014; doi:10.1371/journal.pone.0096748.

17. Levy EW, Pfalzer LA, Danoff J, Springer BA, McGarvey C, Shieh $\mathrm{CY}$, et al. Predictors of functional shoulder recovery at 1 and 12 months after breast cancer surgery. Breast Cancer Res Treat. 2012;134:315-24

18. Miaskowski C, Paul SM, Cooper B, West C, Levine JD, Elboim C, et al. Identification of patient subgroups and risk factors for persistent arm/shoulder pain following breast cancer surgery. Eur J Oncol Nurs. 2014;18:242-53.

19. Smoot B, Paul SM, Aouizerat BE, Dunn L, Elboim C, Schmidt B, et al. Predictors of altered upper extremity function during the first year after breast cancer treatment. Am J Phys Med Rehabil. 2016;95:639-55.

20. Thomas-Maclean RL, Hack T, Kwan W, Towers A, Miedema B, Tilley A. Arm morbidity and disability after breast cancer: new directions for care. Oncol Nurs Forum. 2008;35:65-71.

21. Boquiren VM, Hack TF, Thomas RL, Towers A, Kwan WB, Tilley A, et al. A longitudinal analysis of chronic arm morbidity following breast cancer surgery. Breast Cancer Res Treat. 2016;157:413-25.
22. Gärtner R, Jensen MB, Kronborg L, Ewertz M, Kehlet H, Kroman N. Self-reported arm-lymphedema and functional impairment after breast cancer treatment - a nationwide study of prevalence and associated factors. Breast. 2010;19:506-15.

23. Hayes S, Rye S, Battistutta D, DiSipio T, Newman B. Upper body morbidity following breast cancer treatment is common, may persist longer-term and adversely influences quality of life. Health Qual Life Outcomes. 2010b; doi:10.1186/1477-7525-8-92.

24. Hormes JM, Bryan C, Lytle LA, Gross CR, Ahmed RL, Troxel AB, et al. Impact of lymphedema and arm symptoms on quality of life in breast cancer survivors. Lymphology. 2010;43:1-13.

25. Swisher A, Davison C, Aranda R, Eye D, Erickson M. Frequency and severity of self-reported upper extremity impairments, activity limitations, and participation restrictions following breast cancer treatment. Rehabil Oncol. 2010;28:3-9.

26. Thomas R, Hack TF, Quinlan E, Tatemichi S, Towers A, Kwan WB, et al. Loss, adaptation and new directions: the impact of arm morbidity on leisure activities following breast cancer. Can Oncol Nursing J. 2015;25:49-53.

27. Wennman-Larsen A, Alexanderson K, Olsson M, Nilsson MI, Petersson L-M. Sickness absence in relation to breast and arm symptoms shortly after breast cancer surgery. Breast. 2013;22:767-72.

28. Chan DNS, Lui LYY, So WKW. Effectiveness of exercise programmes on shoulder mobility and lymphoedema after axillary lymph node dissection for breast cancer: systematic review. J Adv Nursing. 2010;66:1902-14.

29. Cheema BS, Kilbreath SL, Fahey PP, Delaney GP, Atlantis E. Safety and efficacy of progressive resistance training in breast cancer: a systematic review and meta-analysis. Breast Cancer Res Treat. 2014;148:249-68.

30. De Groef A, Van Kampen M, Dieltjens E, Christiaens MR, Neven P, Geraerts I, et al. Effectiveness of postoperative physical therapy for upper limb impairments following breast cancer treatment: a systematic review. Arch Phys Med Rehab. 2015;96:1140-53.

31. McNeely M, Campbell K, Ospina M, Rowe BH, Dabbs K, McNeely ML, et al. Exercise interventions for upper-limb dysfunction due to breast cancer treatment. Cochrane Database Syst Rev. 2010;93:1291-7.

32. Harris SR, Schmitz KH, Campbell KL, McNeely ML. Clinical practice guidelines for breast cancer rehabilitation: syntheses of guideline recommendations and qualitative appraisals. Cancer. 2012;118:2312-24.

33. Hagstrom AD, Marshall PWM, Lonsdale C, Cheema BS, Fiatarone Singh MA, Green S. Resistance training improves fatigue and quality of life in previously sedentary breast cancer survivors: a randomised controlled trial. Eur J Cancer Care. 2016;25:784-94.

34. Stuiver MM, Tusscher MR, Agasi-Idenburg CS, Lucas C, Aaronson NK, Bossuyt PM. Conservative interventions for preventing clinically detectable upper-limb lymphoedema in patients who are at risk of developing lymphoedema after breast cancer therapy. Cochrane Database Syst Rev. 2015; doi:10.1002/ 14651858.CD009765.pub2.

35. Torres Lacomba M, Yuste Sanchez MJ, Zapico Goni A, Prieto Merino D, Mayoral del Moral O, Cerezo Tellez E, et al. Effectiveness of early physiotherapy to prevent lymphoedema after surgery for breast cancer: randomised, single blinded, clinical trial. BMJ. 2010; doi:10.1136/bmj.b5396.

36. National Institute for Health and Clinical Excellence (NICE). Early and locally advanced breast cancer: diagnosis and treatment. (Clinical guideline 80.) London: NICE, 2009. http://www.nice. org.uk/CG80. Accessed 2 Aug 2016.

37. Binkley J, Harris S, Levangie P, Pearl M, Guglielmino J, Kraus V, et al. Patient perspectives on breast cancer treatment side effects and the prospective surveillance model for physical rehabilitation for women with breast cancer. Cancer. 2012;118:2207-16. 
38. Exercises after breast cancer surgery (BCC6). Breast Cancer Care, October 2015. Available from: https://www.breastcancercare.org. uk/information-support/publication/exercises-after-breast-cancersurgery-bcc6

39. Todd J, Topping A. A survey of written information on the use of post-operative exercises after breast cancer surgery. Psychotherapy. 2005;91:87-93.

40. Kärki A, Simonen R, Mälkiä E, Selfe J. Postoperative education concerning the use of the upper limb, and exercise and treatment of the upper limb: cross-sectional survey of 105 breast cancer patients. Support Care Cancer. 2004;12:347-54.

41. Brown J, Cheville A, Tchou J, Harris SR, Schmitz KH. Prescription and adherence to lymphoedema self-care modalities among women with breast cancer-related lymphoedema. Support Care Cancer. 2014;22:135-43

42. Sherman K, Koelmeyer L. Psychosocial predictors of adherence to lymphedema risk minimization guidelines among women with breast cancer. Psycho-Oncology. 2013;22:1120-6.

43. Barlow J, Wright C, Sheasby J, Turner A, Hainsworth J. Selfmanagement approaches for people with chronic conditions: a review. Patient Educ Couns. 2002;48(2):177-87.

44. Hammer M, Ercolano E, Wright F, Dickson V, Chyun D, Melkus G. Self-management for adult patients with cancer: an integrative review. Cancer Nurs. 2015;38:E10-26.

45. Ali E, Chew L, Yap K. Evolution and current status of mHealth research: a systematic review. BMJ Innov. 2016;2:33-40.

46. Fiordelli M, Diviani N, Schulz P. Mapping mHealth research: a decade of evolution. J Med Internet Res. 2013;15:e95. doi:10. 2196/jmir.2430.

47. Nasi G, Cucciniello M, Guerrazzi C. The role of mobile technologies in health care processes: the case of cancer supportive care. J Med Internet Res. 2015;17:e26. doi:10.2196/jmir.3757.

48. World Health Organization (WHO). mHealth: New horizons for health through mobile technologies. Based on the findings of the second global survey on eHealth. Geneva, Switzerland: WHO; 2011.

49. Ofcom. The Communications Market Report. 2016. http://www. ofcom.org.uk/research-and-data/cmr/cmr16 Accessed 9 Aug 2016.

50. IMS Institute for Healthcare Informatics. Patient adoption of mHealth: use, evidence and remaining barriers to mainstream acceptance. 2015. http://www.imshealth.com/files/web/IMSH\% 20Institute/Reports/ Patient\%20Adoption\%20of\%20mHealth/ IIHI_Patient_Adoption_of_mHealth.pdf Accessed 2 Aug 2016.

51. Bender J, Yue R, To M, Deacken L, Jadad AR. A lot of action, but not in the right direction: systematic review and content analysis of smartphone applications for the prevention, detection, and management of cancer. J Med Internet Res. 2013; doi:10.2196/jmir.2661.

52. Mobasheri M, Johnston M, King D, Leff D, Thiruchelvam P, Darzi A. Smartphone breast applications - what's the evidence? Breast. 2014;23:683-9.

53. Odeh B, Kayyali R, Nabhani-Gebara S, Philip N. Optimizing cancer care through mobile health. Support Care Cancer. 2015;23: 2183-8.

54. Krebs P, Duncan D. Health app use among US mobile phone owners: a national survey. J Med Internet Res mHealth uHealth. 2015;3:e101. doi:10.2196/mhealth.4924.

55. Singh K, Drouin K, Newmark L, et al. Developing a framework for evaluating the patient engagement, quality, and safety of mobile health applications. The Commonwealth Fund, 2016. Available from: http://www.commonwealthfund.org/publications/issuebriefs/2016/feb/evaluating-mobile-health-apps

56. Wiechmann W, Kwan D, Bokarius A, Toohey SL. There's an app for that? Highlighting the difficulty in finding clinically relevant smartphone applications. West J Emerg Med. 2016;17:191-4.

57. Birnbaum F, Lewis D, Rosen R, Ranney M. Patient engagement and the design of digital health. Acad Emerg Med. 2015;22:754-6.
58. Ribeiro N, Moreira L, Barros A, Almeida A, Santos-Silva F. Guidelines for a cancer prevention smartphone application: a mixed-methods study. Int J Med Informatic. 2016;94:134-42.

59. Timmerman J, Tönis T, Dekker-van Weering M, Stuiver M, Wouters M, van Harten W, et al. Co-creation of an ICT-supported cancer rehabilitation application for resected lung cancer survivors: design and evaluation. BMC Health Serv Res. 2016;16:155. doi: 10.1186/s12913-016-1385-7.

60. Kitzinger J. Qualitative research: introducing focus groups. BMJ. 1995;311:299-302.

61. Johnston M, Mobasheri M, King D, Darzi A. The imperial clarify, design and evaluate (CDE) approach to mHealth app development. BMJ Innov. 2015;1:39-42.

62. Fishbein JN, Nisotel LE, MacDonald JJ, Amoyal Pensak N, Jacobs $\mathrm{JM}$, Flanagan C, et al. Mobile application to promote adherence to oral chemotherapy and symptom management: a protocol for design and development. JMIR Res Protoc. 2017;6:e62. doi:10.2196/ resprot.6198.

63. Attride-Stirling J. Thematic networks: an analytic tool for qualitative research. Qual Res. 2001;1:385-405.

64. Braun V, Clarke V. Using thematic analysis in psychology. Qual Res Psychol. 2006;3:77-101.

65. Tricco A, Antony J, Zarin W, Strifler L, Ghaassemi M, et al. A scoping review of rapid review methods. BMC Med. 2015;13: 224. doi:10.1186/s12916-015-0465-6.

66. Todd J, Scally A, Dodwell D, Horgan K, Topping A. A randomised controlled trial of two programmes of shoulder exercise following axillary node dissection for invasive breast cancer. Physiotherapy. 2008;94:265-73.

67. Lauridsen MC, Christiansen, Hessov I. The effect of physiotherapy on shoulder function in patients surgically treated for breast cancer: a randomized study. Acta Oncol. 2005;44:449-57.

68. Singh C, De Vera M, Campbell KL. The effect of prospective monitoring and early physiotherapy intervention on arm morbidity following surgery for breast cancer: a pilot study. Physiother Can. 2013;65:183-91.

69. Petito EL, Esteves MT, Elias S, Facina G, Nazário ACP, Gutiérrez MGR. The influence of the initiation of an exercise programme on seroma formation and dehiscence following breast cancer surgery. J Clin Nurs. 2014;23:3087-94.

70. Testa A, Iannace C, Di Libero L, Caracciolo. Strengths of early physical rehabilitation programs in surgical breast cancer patients: results of a randomized control study. Eur J Phys Rehabil Med. 2014;50:275-84.

71. Schmitz KH, Ahmed RL, Troxel AB, Cheville A, Lewis-Grant L, Smith $\mathrm{R}$, et al. Weight lifting for women at risk for breast cancer related lymphedema. JAMA. 2010;304:2699-705.

72. Hayes SC, Speck RM, Reimet E, Stark A, Schmitz KH. Does the effect of weight lifting on lymphedema following breast cancer differ by diagnostic method: results from a randomized controlled trial. Breast Cancer Res Treat. 2011;130:227-34.

73. Paramanandam VS, Roberts D. Weight training is not harmful for women with breast cancer-related lymphoedema: a systematic review. J Physiother. 2014;60:136-43.

74. Alpozgen AZ, Ozdincler AR, Karanlik H, Yaman Agaoglu F, Narin AN. Effectiveness of Pilates-based exercises on upper extremity disorders related with breast cancer treatment. Eur J Cancer Care. 2016; doi:10.1111/ecc/12532.

75. Eyigor S, Karapolat H, Yesil H, Uslu R, Durmaz B. Effects of Pilates exercises on functional capacity, flexibility, fatigue, depression, and quality of life in female breast cancer patients: a randomized controlled study. Eur J Phys Rehab Med. 2010;46:481-7.

76. Stan DL, Rausch SM, Sundt K, Cheville AL, Youdas JW, Krause DA, et al. Pilates for breast cancer survivors. Clin J Oncol Nurs. 2012;16:131-41. 
77. Michie S, Richardson M, Johnston M, Abraham C, Francis J, Hardeman W, et al. The behavior change technique taxonomy (v1) of 93 hierarchically clustered techniques: building an international consensus for the reporting of behavior change interventions. Ann Behav Med. 2013;46:81-95.

78. Swift. 2016. Available from: https://developer.apple.com/library/ content/documentation/Swift/Conceptual/ Swift_Programming Language/

79. Xcode IDE. 2016. Available from: https://developer.apple.com/ xcode/

80. van Gemert-Pijnen JE, Nijland N, van Limburg M, Ossebaard HC, Kelders SM, Eysenbach G, et al. A holistic framework to improve the uptake and impact of eHealth technologies. J Med Internet Res. 2011; doi:10.2196/jmir.1672.
81. Shah SG, Robinson I, AlShawi S. Developing medical device technologies from users' perspectives: a theoretical framework for involving users in the development process. Int J Technol Assess Health Care. 2009;25:514-21.

82. Schulman-Green D, Jeon S. Managing cancer care: a psychoeducational intervention to improve knowledge of care options and breast cancer self-management. Psycho-Oncol. 2017;26:173-81.

83. Jansen F, van Uden-Kraan C, van Zwieten V, Witte B, Verdonck-de LI. Cancer survivors' perceived need for supportive care and their attitude towards self-management and eHealth. Support Care Cancer. 2015;23:1679-88.

84. Lee TS, Kilbreath SL, Sullivan G, Refshauge KM, Beith JM. Patient perceptions of arm care and exercise advice after breast cancer surgery. Oncol Nurs Forum. 2010;37:85-91. 